\title{
Taxonomic characteristics of vegetative organs for invasive species of Reynoutria Hook.
}

\section{Таксономические признаки вегетативных органов инвазионных видов рода Reynoutria Hook.}

\author{
Yulia Vinogradova*, Alla Kuklina, Andrey Ryabchenko \\ N.V. Tsitsin Main Botanical Garden of Russian Academy of Sciences, Moscow, Russia
}

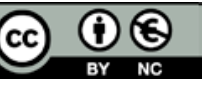

Article Details:

Received:

2021-04-12

Accepted:

2021-04-28

Available online: 2021-05-31

Species of the genus Reynoutria Hook. were originally intentionally introduced from East Asia and in the twentieth century, three of them were successfully naturalized in Europe: $R$. sachalinensis (F. Schmidt) Nakai, $R$. japonica Houtt. and their cultigenous hybrid $R . \times$ bohemica Chrtek \& Chrtková, which arose in the secondary distributional range of the parent species. As the taxa of the genus Reynoutria bloom very late, in late September-October, the characteristics of their leaves - shape, and type of pubescence - are mainly used as diagnostic ones. Identification of the species is often difficult, so this paper aims to identify diagnostic characters of their leaves in the secondary distribution range. Spontaneous invasive populations in Luxembourg, the Czech Republic, and Russia have been investigated. Comparisons have been made with plants growing in the natural range in Japan. Morphological characters were studied using a Keyence VHX-1000E digital microscope and an LEO 1430 VP scanning microscope. R. sachalinensis was found to be well distinguished from other species by its larger leaves with a heart-shaped base and a non-retracted apex. On the underside of the leaf, there are long uniseriate filiform trichomes along the lateral veins or outside the veins and peltate glands with 4-, 6- or 8-cell heads. For $R . \times$ bohemica, the presence of unicellular conical trichomes on the midrib was found to be a diagnostic feature in plants growing in Middle Russia (but not always) and is not applicable to plants from Czech populations, from which this species was actually described! In the taxonomic description of $R$. japonica, it has been suggested that the maximum height of the shoots should be significantly reduced (from $3 \mathrm{~m}$ to $1 \mathrm{~m}$ ), as in the natural range this taxon has prostrate shoots. Plants of the secondary range with tall shoots are likely to be really $R . \times$ bohemica hybrids. It has been suggested that in Eastern Europe $R$. japonica grows generally very rare and predominantly in culture, and the information about most plants from invasive populations described in the literature as $R$. japonica should in fact be attributed to the hybrid complex $R . \times$ bohemica.

Keywords: Reynoutria, leaves, morphometric analysis, trichomes, variability

\section{Введение}

Исследование анатомии и микроморфологии вегетативных органов дает возможность выявить дополнительные диагностические признаки для систематики «трудных» таксонов или видов с позднеосенним цветением (Atalay et al., 2016; Svidenko et al., 2018; Hrytsyna et al., 2019; Vinogradova et al., 2021). Особенно важно получить эти сведения для чужеродных видов с тем, чтобы как можно более раньше диагностировать новый инвазионный таксон и принять меры по контролю его дальнейшего расселения.

Виды рода Рейнутрия Reynoutria Hook. (= Fallopia Adans.) семейства Polygonaceae - это многолетние травянистые растения с мощным ветвистым подземным корневищем. Стебли многочисленные,

\footnotetext{
*Corresponding Author: Yulia Vinogradova, Department of the Native Flora, N.V. Tsitsin Main Botanical Garden of Russian Academy of Sciences, Moscow, Russia

$\triangle$ gbsad@mail.ru
} 
высотой 1-3 м, полые, прямостоячие, вверху ветвистые и часто дуговидно изогнутые, внизу обычно с красноватыми пятнами или штрихами (Vinogradova et al., 2010).

В естественном ареале в Корее $R$. sachalinensis (F. Schmidt) Nakai встречается в виде додекаплоидов с $2 \mathrm{n}=132 ; \mathrm{y} R$. japonica Houtt. отмечены тетраплоиды $(2 \mathrm{n}=44)$, гексаплоиды $(2 \mathrm{n}=66)$ и октоплоиды $(2 \mathrm{n}=88) ; R$. forbesii встречается как гексаплоид $(2 \mathrm{n}=66)$ и октоплоид $(2 \mathrm{n}=88)$. Очевидной корреляции между уровнями плоидности этих таксонов и морфологическими признаками не существует, за исключением того, что тетраплоиды $R$. japonica имеют несколько более толстые листья (Kim and Park, 2000).

ВЕвропенатурализовалисьтри вида: R. sachalinensis, $R$. japonica и их культигенный гибрид $R . \times$ bohemica Chrtek \& Chrtková, возникший во вторичном ареале родительских видов. Гибридизация чужеродных видов привела в этом случае к формированию таксона с высоким инвазионным потенциалом, выше, чем у родительских видов (Buhk and Thielschb, 2015). R. japonica отмечен в Европе в 31 стране, в 12 из них этот вид рассматривается как инвазионный. $R$. sachalinensis отмечен в Европе в 29 странах, в 18 из них этот вид рассматривается как инвазионный. $R$. × bohemica отмечен в Европе в 26 странах, в 10 из них он включен в список инвазионных видов (САВI, 2021).

Несмотря на высокий инвазионный потенциал, рейнутрию до сих пор используют в декоративных целях. Молодые побеги готовят в пищу как спаржу. В традиционной китайской медицине R. japonica используется для лечения гнойных заболеваний, боли в горле, зубной боли, язвы, геморроя, хронического бронхита (Patocka et al., 2017; Zhang et al., 2019). Побеги и корни обладают антиоксидантными, антивирусными, противовоспалительными, кардиопротекторными и противоопухолевыми свойствами (NawrotHadzik et al., 2018). В современной медицине рейнутрию используют для лечения нейрокардиоваскулярных и воспалительных заболеваний, гриппа, гиперлипидемии и ожогов кожи (Saito et al., 1997; Nhiem et al., 2014). На основе рейнутрии выпускают препарат под торговой маркой Milsana*, который эффективен для борьбы с мучнистой росой томатов (Konstantinidou-Doltsinis et al., 2006). Имеются данные, что рейнутрию можно использовать в качестве фиторемедиатора дли снижения содержания тяжелых металлов (Ibrahimpašić et al., 2020).
Поскольку таксоны рода Reynoutria зацветают очень поздно, в конце сентября-октябре, в качестве диагностических признаков, в основном, используются особенности их листовой пластинки - форма и характер опушения. Выявлены три основных типа трихом:

1. конические одноклеточные трихомы,

2. однорядные нитевидные трихомы, состоящие из 1-8 клеток,

3. пельтатные железистые трихомы.

Типы трихом и их распределение могут быть полезны для различения таксонов в секции (Moon et al., 2011). Отмечено, что R. sachalinensis характеризуется специфическимианатомическими особенностями: наличием в листьях друз оксалата кальция и крахмальных гранул (Cîrlig et al., 2016).

В нашей прошлой работе (Vinogradova et al., 2010) мы характеризовали по признакам вегетативных органов следующие различия между таксонами:

- $\quad$ R. sachalinensis (F. Schmidt) Nakai. Листья очень крупные, длиной до 20-45 см, с явственно сердцевидным основанием, нижняя сторона листовой пластинки с длинными (часто более 2 мм) многоклеточными волосками.

- R. japonica Houtt. var. japonica. Растения высотой 1-4 м. Листовая пластинка яйцевидная или овальная с оттянутой треугольной верхушкой, снизу голая или по жилкам папиллозная, основание усеченное или широко клиновидное, часто несколько неравнобокое. Самые крупные листья на главном побеге длиной до 20-25 см, на боковых побегах листья мельче.

- $\quad$. japonica var. compacta (Hook. f.) Moldenke. Растения высотой до 1 м. Листья довольно мелкие, длина самых крупных из них не превышает 10 см.

- $R . \times$ bohemica Chrtek \& Chrtková. Листья c усеченным, реже сердцевидным или ширококлиновидным основанием. Листья снизу хотя бы по жилкам с густыми острыми коническими 1-3-клеточными волосками. У теневых растений листья иногда почти голые, но конические волоски сохраняются хотя бы в основании листовой пластинки. В начале мая при развертывании листовых пластинок, по крайней мере, у части растений с обеих сторон листа хорошо заметны более длинные простые волоски длиной 1-2 мм. 


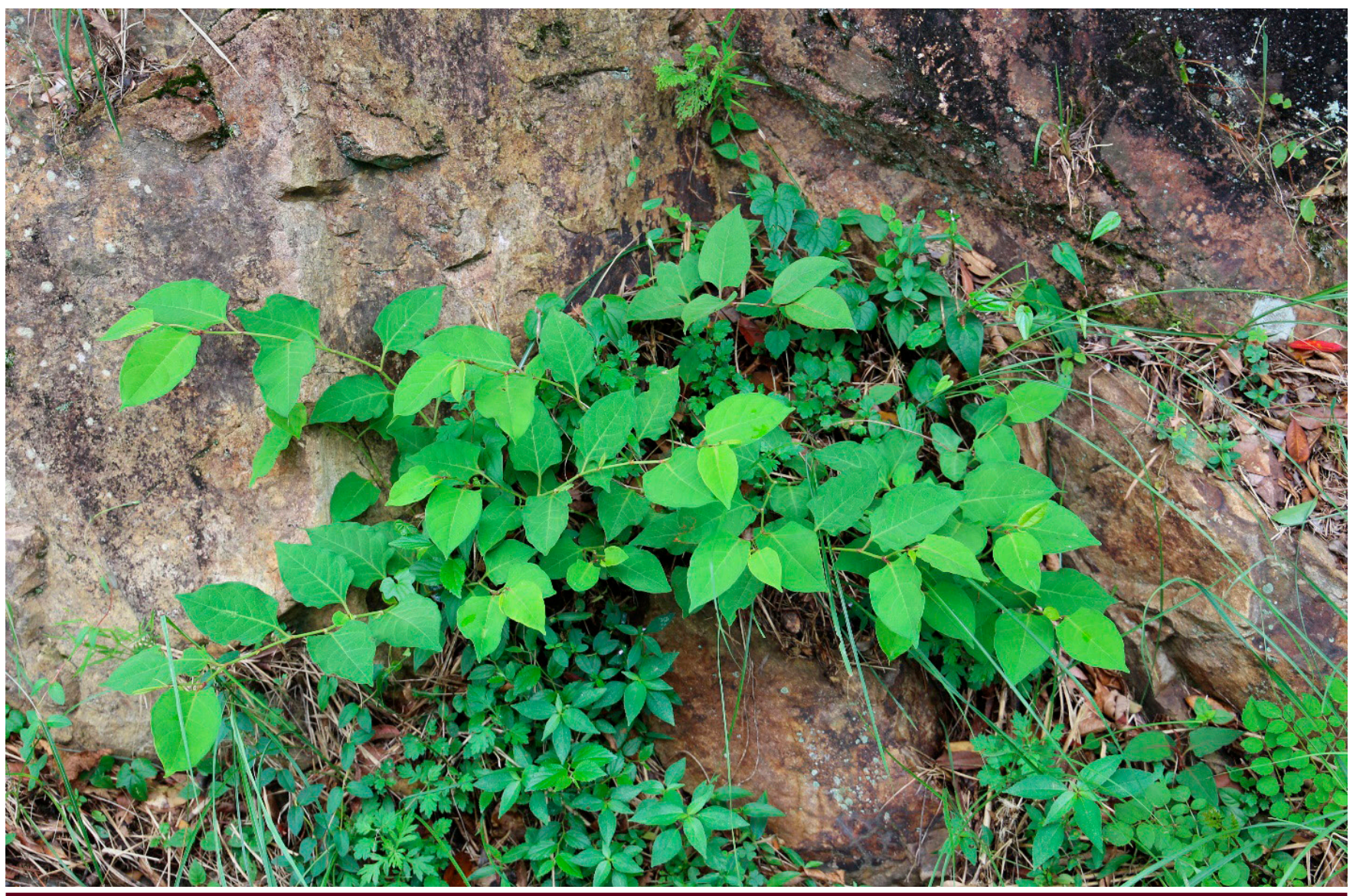

Рисунок 1 Стелющиеся побеги Reynoutria japonica Houtt. в естественном ареале

Figure 1 Prostrate shoots of Reynoutria japonica Houtt. in the native distribution range

Исследования, проведенные нами в последние годы, показали, что этот ключ не всегда применим и нуждается в корректировке. Так, в 2016 г. нам посчастливилось наблюдать $R$. japonica var. japonica в ее естественном ареале в окрестностях Токио и на острове Сикоку. На равнине растения имели
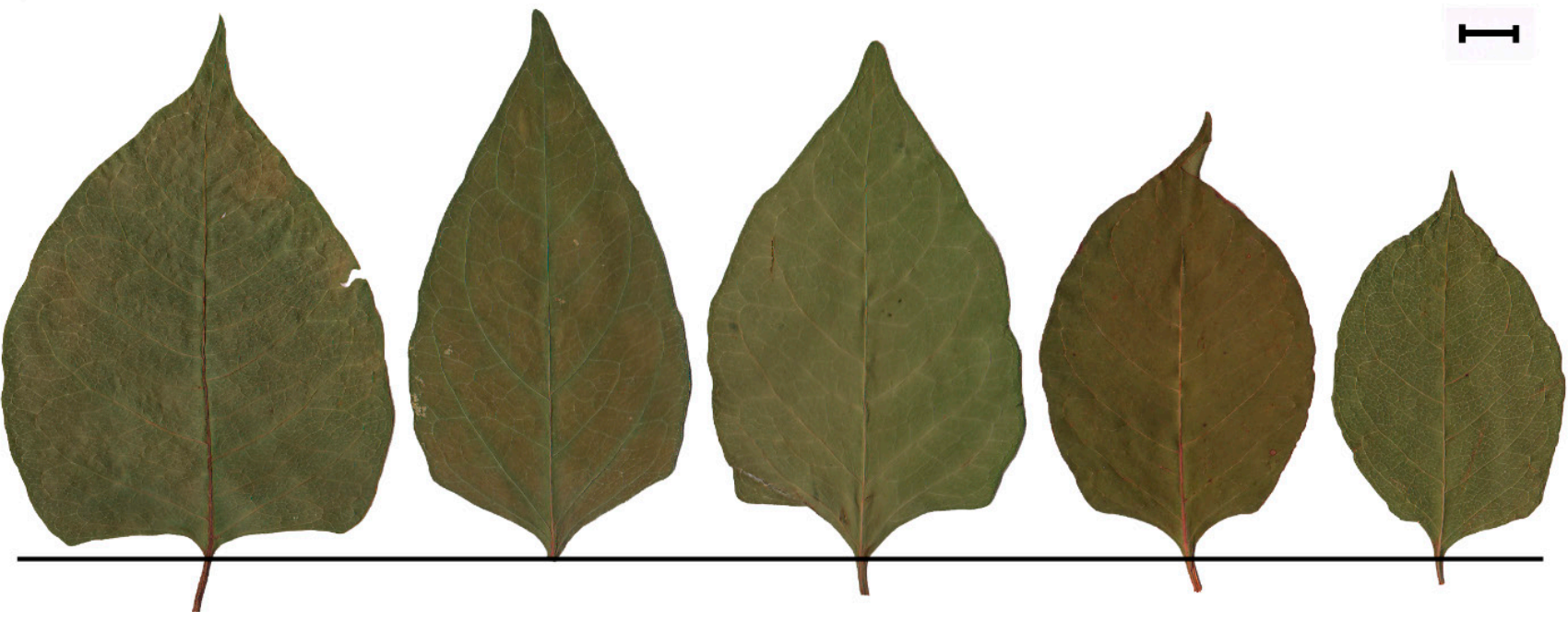

Рисунок 2 Форма листовой пластинки Reynoutria japonica Houtt. в естественном ареале (каждый лист собран в разных клонах)

Figure 2 Leaf blades of Reynoutria japonica Houtt. from the native distribution range (each leaf collected from a different clonas) 
стелющиеся побеги (Рисунок 1), а в нижнем поясе гор высота растений не превышала 1 м. Основание листовой пластинки у всех особей было клиновидным (Рисунок 2) и не очень схожим с теми листьями, которые мы наблюдаем у растений в Средней России. Это подтолкнуло нас к более детальному изучению признаков листа таксонов рода Reynoutria во вторичном ареале.

\section{Материал и методика}

\section{Растительный материал}

$R . \times$ bohemica: листья собраны в 5 локальных популяциях (или клонах) г. Москвы и в 9 популяциях Московской области: в Балашихинском, Дмитровском, Долгопрудном, Мытищинском, Одинцовском (2 местообитания), Орехово-Зуевском, Пушкинском и Раменском p-нах. В анализ были включены также листья, собранные авторами в г. Вьянден и в зарослях по реке Сюр (Люксембург), в г. Прага и в окрестностях г. Карловы Вары (Чехия) и культивируемые клоны в поселках Южного Берега Крыма.

$R$. japonica var. japonica: листья собраны авторами в естественном ареале в пос. Минами (о-в Сикоку, Япония) и в окрестностях г. Токио. Этот же таксон, согласно этикетке, содержится в коллекции Никитского ботанического сада (этот образец мы также включили в анализ).

R. japonica var. compacta: листья с растений, культивируемых в Главном ботаническом саду Российской академии наук (ГБС РАН,
Москва, Россия) и в ботаническом саду Карлова университета (Прага, Чехия).

R. sachalinensis: листья собраны авторами в трех локальных популяциях (интродукционная популяция в ГБС РАН, г. Звенигород Московской области и район Новокосино г. Москвы) и получены из естественного ареала (окрестности г. Южно-Сахалинск).

Объем исследованного материала был увеличен за счет просмотра гербарных образцов таксонов рода Reynoutria, хранящихся в Гербарии ГБС РАН (MHA) и в Гербарии МГПУ (MOSP).

\section{Морфометрический анализ}

Из каждой локальной популяции (= клона) брали по 3 осевых побега и просматривали по 2 листа с каждого на цифровом микроскопе Keyence VHX1000 Е при увеличении до х 200. Листья с боковых побегов в анализ не включали, поскольку их форма отличается от формы листьев главного побега. Форму основания листовой пластинки определяли по углу, сформированному средней жилкой и осью, проходящую от основания черешка к краю листовой пластинки. Для исследования ультраскульптуры листовой пластинки использовали сканирующий электронный микроскоп LEO 1430 VP.

\section{Статистический анализ}

Результаты обработаны методами математической статистики в программе PAST.
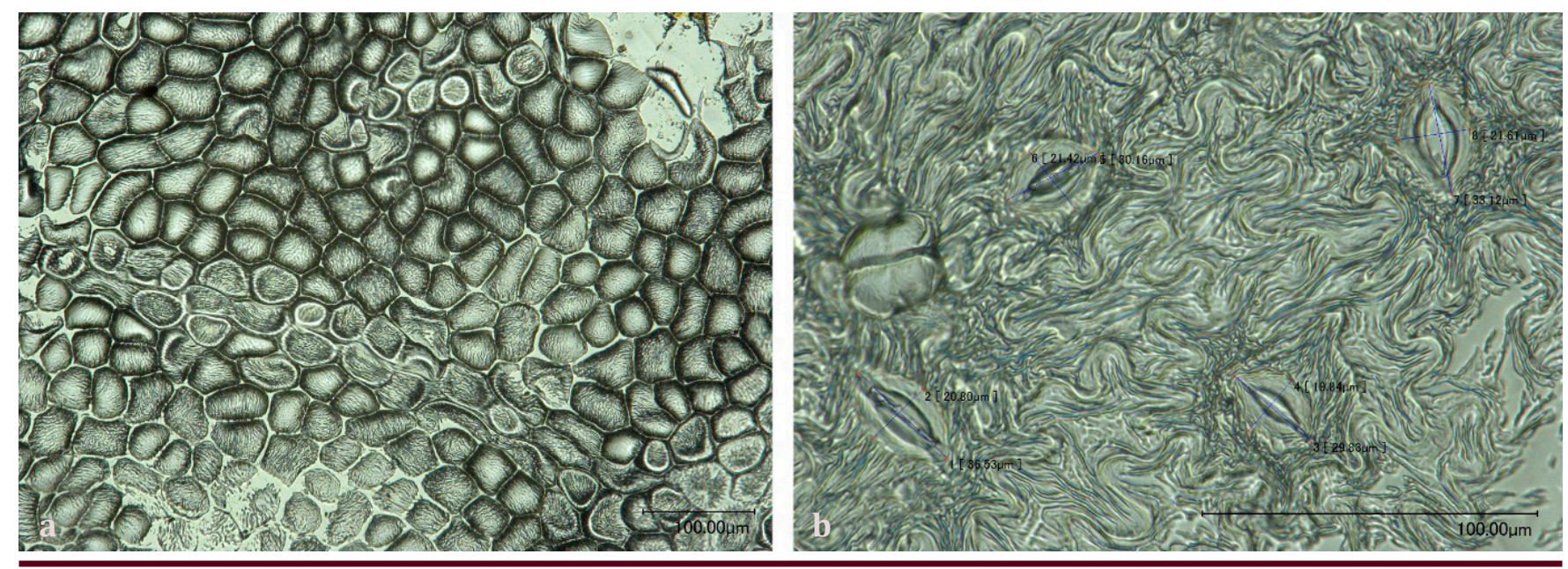

Рисунок 3 Листовая пластинка Reynoutria $\times$ bohemica Chrtek \& Chrtková:

$\mathrm{a}$ - верхняя сторона без устьиц; $\mathrm{b}$ - нижняя сторона с аномоцитными устьицами и пельтатной железкой

Figure 3 Leaf blade of Reynoutria $\times$ bohemica Chrtek \& Chrtková:

a - upper side without stomata; b - lower side with anomocytic stomata and peltate glandular trichome 

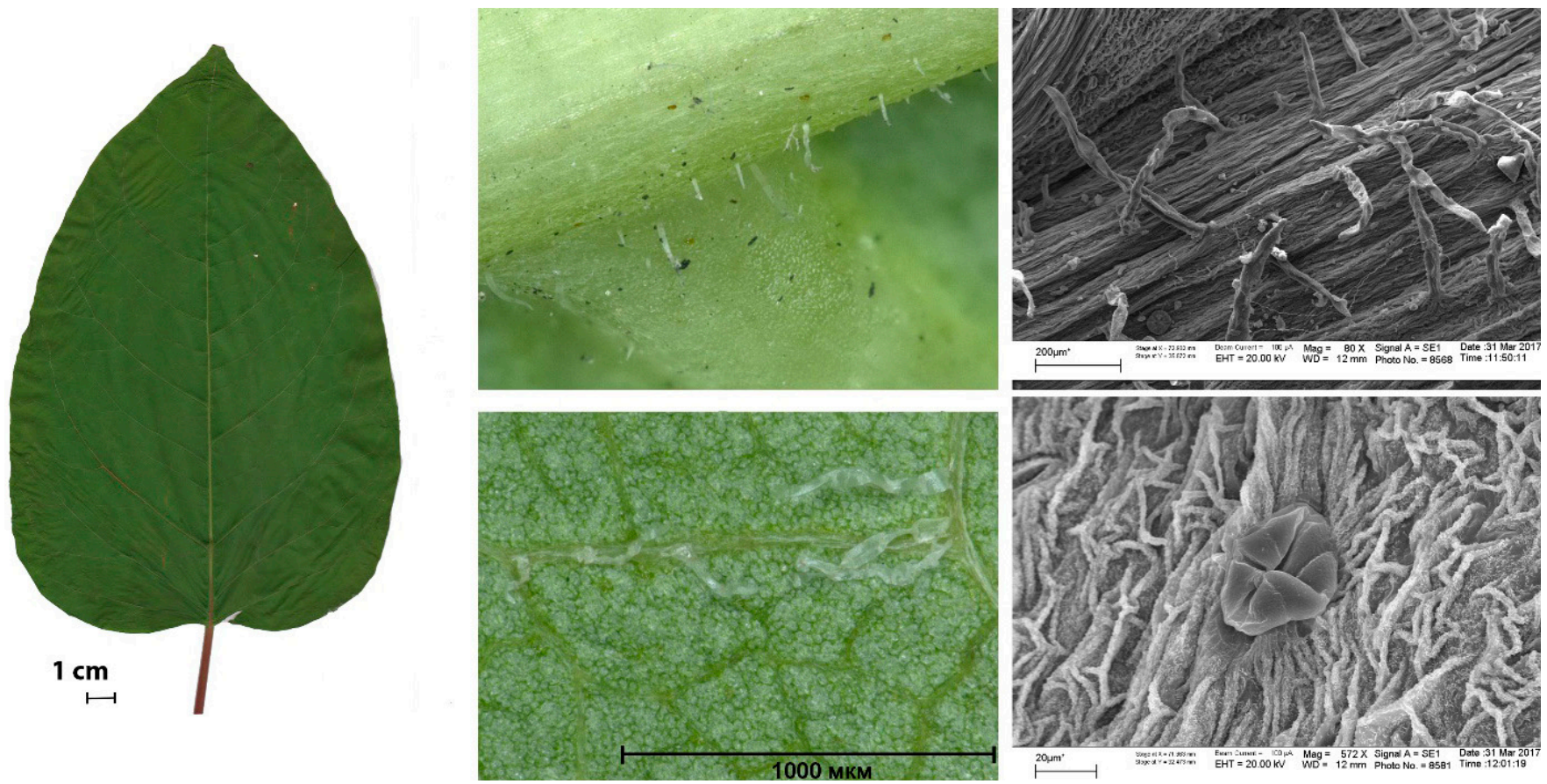

Рисунок 4 Лист Reynoutria sachalinensis (F. Schmidt) Nakai: сердцевидное основание, однорядные длинные трихомы и пельтатная железка с восьмиклеточной головкой на нижней стороне листа

Figure 4 Leaf blades of Reynoutria sachalinensis (F. Schmidt) Nakai: heart-shaped base, uniseriate filiform trichomes and peltate glandular trichome with 8-celled head on the lower side of leaves

\section{Результаты и обсуждение}

У всех видов листья черешковые, верхняя сторона листовой пластинки голая, листья гипостоматические, т.е. устьица у них располагаются только на нижней стороне листовой пластинки (Рисунок 3).

R. sachalinensis хорошо отличается по сердцевидному основанию листа (Рисунок 4): угол между средней жилкой и осью от основания черешка к краю листовой пластинки у всех образцов тупой, т.е. $>90^{\circ}$ и в среднем составляет $97.7 \pm 2.7^{\circ}$ (от 95 до $103^{\circ}$ ). Верхушка листа не оттянутая.

Хорошо отличается таксон и по микроморфологическим признакам: на нижней стороне листовой пластинки имеется две группы трихом:

1. короткие по средней жилке,

2. длинные по второстепенным жилкам или вне жилок (Рисунок 4).

Средняя длина длинных трихом у звенигородского образца 256.6 (149-494) мкм, у новокосинского образца - 373.5 (210-494) мкм. Очень длинных трихом (до 2 мм), которые упоминаются в определителях, мы не находили. Пельтатные железки имеют чаще всего головку из 4 клеток, но встречаются железки и с 6-клеточной, и с 8-клеточной головкой. Вместе с характерными признаками генеративных органов - опушенными цветоножками и опушенными листочками околоцветника внешнего круга, наличием обильной пыльцы и способностью к активному плодоношению (Vinogradova et al., 2016) особи, принадлежащие к этому виду, определяются однозначно.

$R$. japonica var. compacta выделяется среди других таксонов по плотной текстуре и по форме листовой пластинки. Листья у этого растения кожистые и б/м округлые, а нередко ширина листа даже превышает его длину (Рисунок 5). На нижней стороне листа имеются пельтатные железки, но трихомы отсутствуют, в том числе и по жилкам.

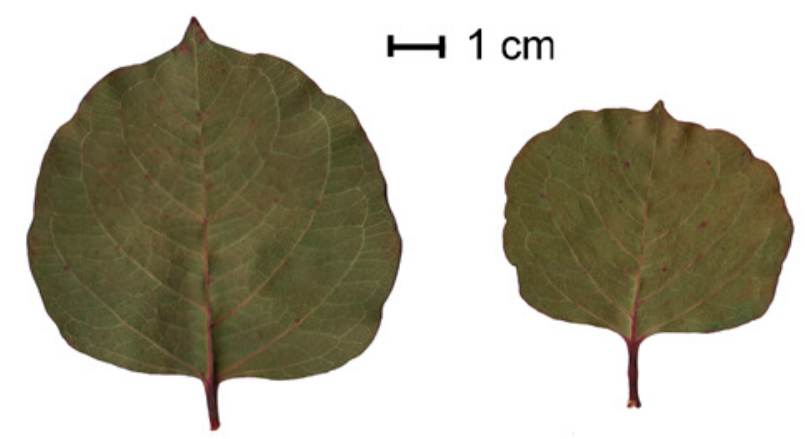

Рисунок 5 Листья Reynoutria japonica var. compacta (Hook. f.) Moldenke

Figure 5 Leave blades of $R$. japonica var. compacta (Hook. f.) Moldenke 
$R$. japonica var. japonica в естественном ареале (Рисунок 2) имеет клиновидное основание листа, и угол между средней жилкой и осью от основания черешка к краю листовой пластинки у всехобразцов острый, т.е. $<90^{\circ}$, и в среднем составляет $63.4 \pm 4.5^{\circ}$ (от 54 до $79^{\circ}$ ). Единственный образец этого таксона из вторичного ареала, который, согласно документации, намеренно интродуцирован непосредственно из Японии, собран нами в Никитском ботаническом саду и также характеризуется острым углом $\left(70^{\circ}\right)$, однако имеет более округлую форму. На немногочисленных гербарных образцах, собранных непосредственно в Японии (MHA, MW, MOSP), этот признак также прослеживается.

Форма листьев всех остальных образцов варьирует настолько сильно, что по этому признаку разграничивать во вторичном ареале $R$. japonica var. japonica от $R . \times$ bohemica достаточно проблематично (Рисунок 6). Поэтому остальные исследованные нами образцы из европейской части вторичного ареала мы предварительно относим к гибридогенному комплексу $R . \times$ bohemica, включающему бэккроссы с родительскими видами.

R. × bohemica: форма основания листовой пластинки варьирует от слабо сердцевидной (угол $97^{\circ}$ ) до округло-клиновидной (угол $73^{\circ}$ ), в среднем $84.2 \pm 1.6^{\circ}$. Форма варьирует даже в пределах одного клона, что мы наблюдали в многокилометровой заросли в долине реки Сюр в Люксембурге (Рисунок 6 m-p). К тому же листья, формирующиеся к концу вегетационного сезона (на боковых побегах или на верхушках осевых побегов), нередко значительно отличаются по форме от листьев срединной формации на осевых побегах (Рисунок 6 i-l). Верхушка листа оттянутая.

Напротив, микроморфологические признаки листьев у всех образцов варьируют слабо. На верхней стороне листовой пластинки трихомы отсутствуют. На нижней стороне листа имеются пельтатные железки, расположенные вне жилок. Число их составляло от 3 до 5 в мм², а диаметр от 40 до 50 мкм (Таблица 1). Острые конические одноклеточные трихомы по главной жилке отсутствуют урастений, собранных в Чехии, а также

Таблица 1 Признаки листьев Reynoutria $\times$ bohemica Chrtek \& Chrtková из различных популяций Восточной Европы Table 1 Leaf characteristics of Reynoutria $\times$ bohemica Chrtek \& Chrtková from different populations in Eastern Europe

\begin{tabular}{|c|c|c|c|c|}
\hline Исследованные популяции & $\begin{array}{c}\text { Географические } \\
\text { координаты }\end{array}$ & $\begin{array}{c}\text { *Угол } \\
\text { в основании } \\
\text { листа, градусы } \\
\end{array}$ & $\begin{array}{c}\text { Конические } \\
\text { трихомы по } \\
\text { главной жилке } \\
\end{array}$ & $\begin{array}{c}\text { Пельтатные железки } \\
\text { с 4-х клеточной } \\
\text { головкой } \\
\end{array}$ \\
\hline Люксембург, река Сюр & $\begin{array}{l}\text { N } 49.9093 \\
\text { E } 5.9272\end{array}$ & $95-103$ & нет & есть \\
\hline $\begin{array}{l}\text { Чехия, Прага, Ботанический } \\
\text { институт }\end{array}$ & $\begin{array}{l}\text { N } 50.0717 \\
\text { E } 14.4216\end{array}$ & $75-87$ & нет & есть \\
\hline $\begin{array}{l}\text { Чехия, Карловы Вары, } \\
\text { у автобусного вокзала }\end{array}$ & $\begin{array}{l}\text { N } 50.2300 \\
\text { E } 12.8626 \\
\end{array}$ & 77-89 & нет & есть \\
\hline Чехия, Карловы Вары, институт & $\begin{array}{l}\text { N } 50.2300 \\
\text { E } 12.8724\end{array}$ & $82-88$ & нет & есть \\
\hline $\begin{array}{l}\text { Московская область, Орехово- } \\
\text { Зуево, Хотеичи }\end{array}$ & $\begin{array}{l}\text { N } 55.5028 \\
\text { E } 38.7936\end{array}$ & $76-90$ & нет & есть \\
\hline Московская область, Реутов & $\begin{array}{l}\text { N } 55.7519 \\
\text { E } 37.8628\end{array}$ & $75-86$ & есть & есть \\
\hline Московская область, Орудьево & $\begin{array}{l}\text { N } 56.4474 \\
\text { E } 37.5142\end{array}$ & $75-80$ & есть & есть \\
\hline Московская область, Пушкино & $\begin{array}{l}\text { N } 56.0266 \\
\text { E } 37.8328 \\
\end{array}$ & $77-85$ & есть & есть \\
\hline Москва, Новокосино & $\begin{array}{l}\text { N } 55.7339 \\
\text { E } 37.8473\end{array}$ & $70-82$ & есть & есть \\
\hline Москва Восточное Бирюлево & $\begin{array}{l}\text { N } 55.5995 \\
\text { E } 37.6746 \\
\end{array}$ & $87-90$ & есть & есть \\
\hline Алушта, Крым & $\begin{array}{l}\text { N } 44.6711 \\
\text { E } 34.3979\end{array}$ & $86-90$ & есть & есть \\
\hline
\end{tabular}

Примечание: * угол между средней жилкой и осью от основания черешка к краю листовой пластинки 

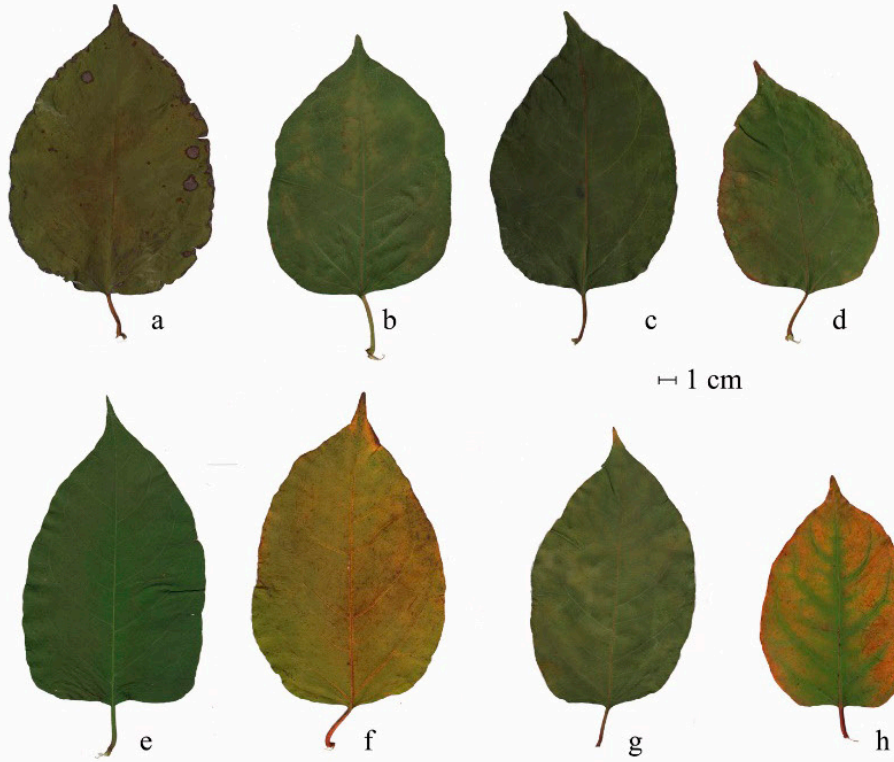

$\mapsto 1 \mathrm{~cm}$
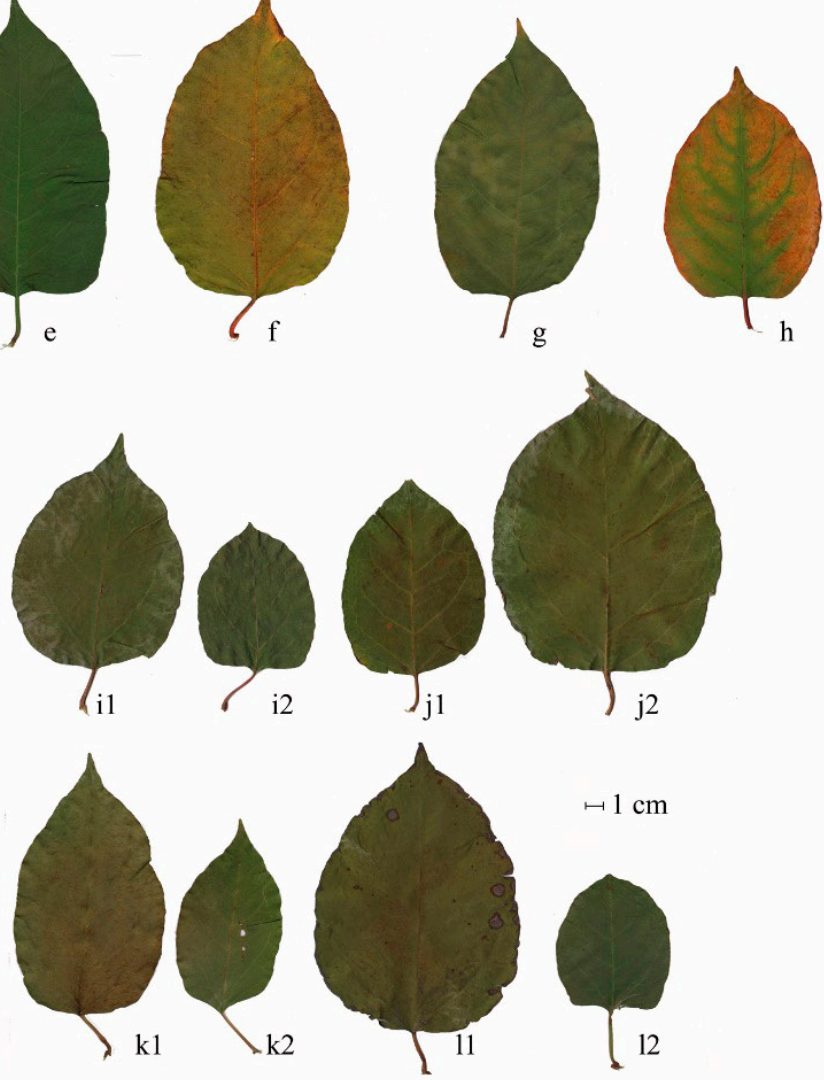

$\mapsto 1 \mathrm{~cm}$
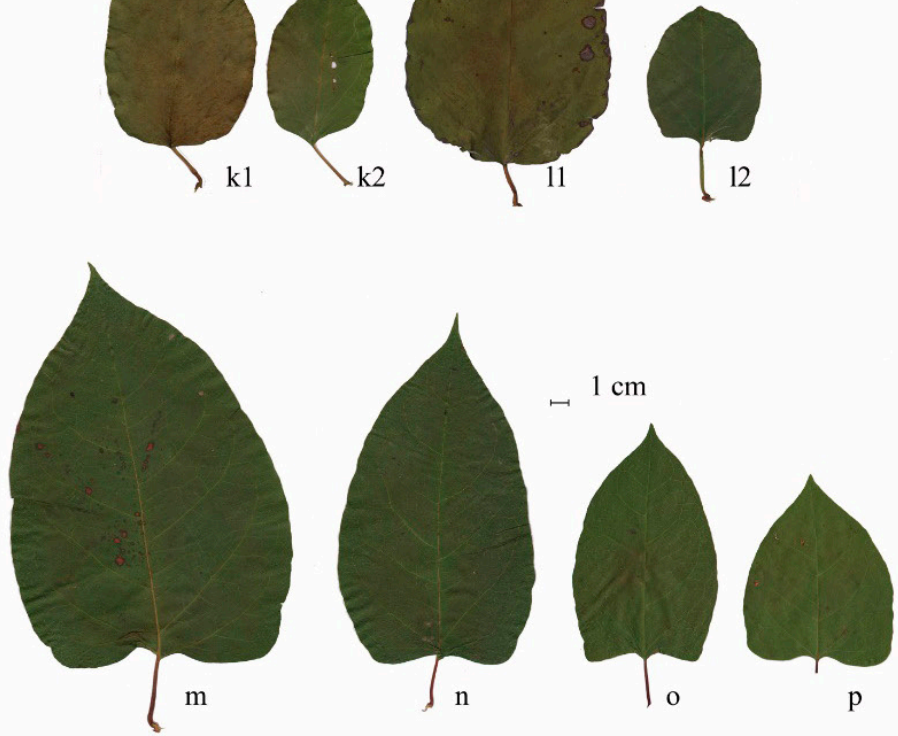

$\mathrm{p}$

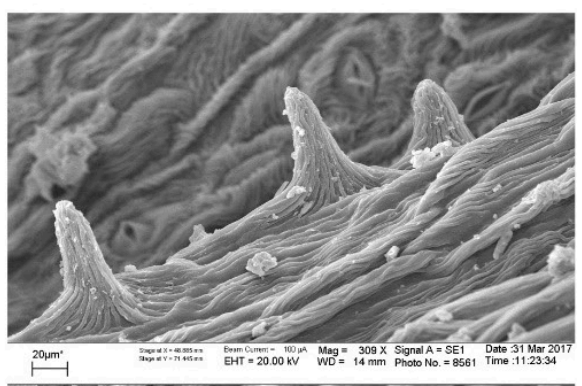

$\mathbf{r}$

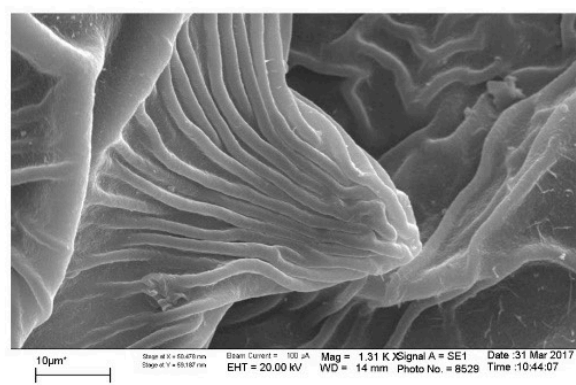

q
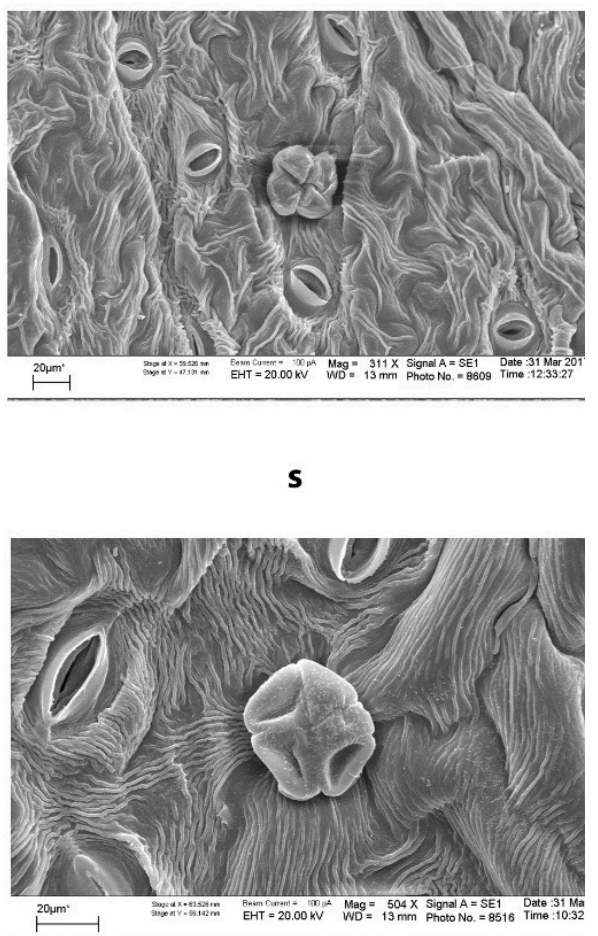

Рисунок 6 Листья Reynoutria $\times$ bohemica Chrtek \& Chrtková:

$\mathrm{a}-\mathrm{h}$ - разные клоны из Московской области; i-l - разные клоны из Средней России (с индексом 1 с осевых побегов, a с индексом 2 - с боковых побегов того же растения); $\mathrm{m}-\mathrm{p}$ - одна прибрежная популяция по реке Сюр (Люксембург) с особей, произрастающих не менее, чем в 50 м друг от друга; r-q - конические одноклеточные трихомы по средней жилке; s-t - устьица и пельтатные железки с четырехклеточной головкой

Figure 6 Leaves of Reynoutria $\times$ bohemica Chrtek \& Chrtková:

$\mathrm{a}-\mathrm{h}$ - different clones from the Moscow Region; i-l - different clones from Central Russia (with index 1 from axial shoots and index 2 from lateral shoots of the same individual); $m-p$ - one coastal population along the Syur River (Luxembourg) from individuals growing at least $50 \mathrm{~m}$ apart each other; $\mathrm{r}-\mathrm{q}$ - conical unicellular trichomes along the middle vein; s- $\mathrm{t}$ - stomata and peltate glandular trichomes with 4-celled head 
в одной из популяций Московской области (из Орехово-Зуево). На гербарных листах, хранящихся в MHA, MW и MOSP, этот тип трихом отмечен лишь у $40 \%$ образцов.

Полученные нами результаты позволяют предположить, что интродуцированная в Англию более 100 лет назад $R$. japonica var. japonica компенсировала отсутствие первоначальной генетической изменчивости обширной серией межвидовой гибридизации с интродуцированной позднее $R$. sachalinensis и образованием гибрида $R . \times$ bohemica, способного кобратному скрещиванию c родительскими видами и генерированию разнообразных генотипов. Это подтверждается как различным уровнем плоидности комплекса $R . \times$ bohemica - от тетраплоидов до октоплоидов, так и его генетическим разнообразием. В Чехии, например, в 88 изученных клонах выявлено 33 мультилокусных генотипа (Mandák et al., 2003, 2005; Bailey, 2012). Однако сведения по уровню плоидности рейнутрии в Словакии, в Криваньских горах, иные. С использованием метода проточной цитометрии показано, что заросли рейнутрии состоят из трех таксонов, каждый из которых представлен только одним цитотипом: гексаплоидным $(2 \mathrm{n}=6 \mathrm{x} \sim 66)$ у $R \times$ bohemica (23 клона), октоплоидным $(2 \mathrm{n}=8 \mathrm{x} \sim 88)$ у R.japonica var. japonica (18 клонов) и тетраплоидным $(2 \mathrm{n}=$ $4 \mathrm{x} \sim 44$ ) у R. sachalinensis (2 клона). Морфометрия 23 признаков листьев продемонстрировала, что наиболее надежным диагностическим признаком Reynoutria является опушение листа. Признано, что R. ×bohemica очень часто путают с $R$. japonica var. japonica, присутствие которой вне культуры переоценивается (Mered'a et al., 2019).

В естественном ареале изучаемые таксоны еще более разнообразны: они представлены особями с различными уровнями плоидности и более разнообразнымижелезками. Так,мыне обнаружили на листьях пельтатных железок с 2-клеточной и с 14-ти клеточной головкой, которые отмечены корейскими учеными (Moon et al., 2011). Различий между видами по этому признаку мы также не отметили: все таксоны имели железки с 4-х клеточной головкой, только у R. sachalinensis, как исключение, наблюдаются железки с с 6-ти и с 8-ми клеточными головками. Напротив, в естественном ареале в Корее у $R$. japonica обнаружены только восьмиклеточные пельтатные железки, а у $R$. sachalinensis - четырех- или восьмиклеточные железки (Khalil et al., 2020).

\section{Выводы}

Ключ для определения таксонов рода Reynoutria во вторичном ареале по признакам листовой пластинки нуждается в некоторой корректировке. Во-первых, необходимо отказаться от указания такой значительной высоты побегов (1-4 м) для $R$. japonica var. japonica, и определить ее высоту в 1,0-1,5 м. Во-вторых, в ключ следует включить отмеченные нами различия в строении пельтатных железок - у $R . \times$ bohemica они имеют 4-х клеточную головку, тогда как у $R$. sachalinensis, помимо 4-х клеточных головок, встречаются железки с 6-ти и с 8-ми клеточными головками. В-третьих, для $R \times$ bohemica наличие конических волосков на средней жилке является диагностическим признаком у растений, произрастающих в Средней полосе России (но и то не всегда), однако не характерен для из чешских популяций, откуда этот вид, собственно, и был описан. Возможно, в Восточной Европе R. japonica вообще произрастает крайне редко, и преимущественно в культуре, а сведения по большинству растений, описываемых в литературных источниках как $R$. japonica, на самом деле следует относить к гибридогенному комплексу $R . \times$ bohemica.

\section{Благодарности}

Работа поддержана двусторонним проектом Министерства образования РФ и Министерства образования Словакии и международным грантом РФФИ № 19-54-26010.

\section{Литература}

ATALAY, Z., CELEP, F., BARA, F., DOĞAN, M. 2016. Systematic significance of anatomy and trichome morphology in Lamium (Lamioideae; Lamiaceae). In Flora - Morphology, Distribution, Functional Ecology of Plants, vol. 225, p. 60-75. https://doi.org/10.1016/j.flora.2016.10.006

BAILEY, J. 2012. The Japanese knotweed invasion viewed as a vast unintentional hybridisation experiment. In Heredity, p. 1-6. https://doi.org/0018-067X/12

BUHK, C., THIELSCH, A. 2015. Hybridisation boosts the invasion of an alien species complex: Insights into future invasiveness. In Perspectives in Plant Ecology, Evolution and Systematics, vol. 17(4), p. 274-283. https://doi.org/10.1016/j.ppees.2015.05.001

CABI. Invasive Species Compendium. Reynoutria. Accessed 01.05.2021.

https://www.cabi.org/isc/datasheet/108332

CÎRLIG, N., CALALB, T., TELEUTA, A. 2016. Biometric and anatomical study of the species of Polygonum 
sachalinensis F. Schmidt. In Journal Botany, vol. 8(13), p. 64-71.

HRYTSYNA, M., SKYBITSKA, M., SALAMON, I. 2019. Morphological and anatomical structural features of shoots of species of the genus Thymus L., introduced in Botanical Garden of Lviv National University named after Ivan Franko. In Agrobiodiversity for Improving Nutrition, Health and Life Quality, vol. 3, p. 38-50.

https://doi.org/10.15414/

agrobiodiversity.2019.2585-8246.038-050

IBRAHIMPAŠIĆ, J., JOGIĆ, V., TOROMANOVIĆ, M., DŽAFEROVIĆ, A., MAKIĆ, H., DEDIĆ, S. 2020. Japanese knotweed (Reynoutria japonica) as a phytoremediator of heavy metals. In Journal of Agricultural, Food and Environmental Sciences, vol. 74(2), p. 45-53.

KHALIL, A.A.K., AKTER, K.-M., KIM, H.-J., PARK, W.S., KANG, D.-M., KOO, K.A., AHN, M.-J. 2020. Comparative inner morphological and chemical studies on Reynoutria species in Korea. In Plants, vol. 9(2), p. 222. https://doi.org/10.3390/plants9020222

KIM, J.Y., PARK, CH-W. 2000. Morphological and chromosomal variation in Fallopia section Reynoutria (Polygonaceae) in Korea. In Brittonia, vol. 52(1), p. 34-48.

KONSTANTINIDOU-DOLTSINIS, S., MARKELLOU, E., KASSELAKI, A.-M. FANOURAKI, M., KOUMAKI, C., A. SCHMITT, A., LIOPA-TSAKALIDIS, A., MALATHRAKIS, N. 2006. Efficacy of Milsana ${ }^{\circledR}$, a formulated plant extract from Reynoutria sachalinensis, against powdery mildew of tomato (Leveillula taurica). In BioControl, vol. 51, p. 375-392.

MANDÁK, B., PYŠEK, P., LYSAK, M., SUDA, J., KRACHULCOVA, A., BÍMOVÁ, K. 2003. Variation in DNA-ploidy levels of Reynoutria taxa in the Czech Republic. In Annals of Botany, vol. 92(2), p. 265-272. https://doi.org/10.1093/aob/mcg141

MANDÁK, B., BÍMOVÁ, K., PYŠEK, P., STEPANEK, J., PLACKOVA, I. 2005. Isoenzyme diversity in Reynoutria (Polygonaceae) taxa: escape from sterility by hybridization. In Pl. Syst. Evol., vol. 253, p. 219-230. https://doi.org/10.1007/s00606-005-0316-6

MEREĎA, P.JR., KOLÁRIKOVÁ, Z., HODÁLOVÁ, I. 2019. Cytological and morphological variation of Fallopia sect. Reynoutria taxa (Polygonaceae) in the Krivánska Malá Fatra Mountains(Slovakia).InBiologia,vol.74,p.215-236. https://doi.org/10.2478/s11756-018-00168-w

MOON, H-K., PARK, J.H., PARK, CH-W. 2011. Trichome morphology of Fallopia sect. Reynoutria (Polygonaceae) in Korea. In Korean J. Pl. Taxon, vol. 41(1), p. 51-57.

NAWROT-HADZIK, I., GRANICA, S., DOMARADZKI, K. PECIO, Ł., MATKOWSKI, A. 2018. Isolation and determination of phenolic glycosides and anthraquinones from rhizomes of various Reynoutria species. In Planta Medica, vol. 84(15), p. 1118-1126. https://doi.org/10.1055/a-0605-3857
NHIEM, N. X., VAN KIEM, P., VAN MINH, C., HOAI, N. T., DUC, H. V., TAI, B. H., KIM, S. H. 2014. Anti-influenza sesquiterpene from the roots of Reynoutria japonica. In Natural Product Communications, vol. 9(3), 1934578X1400900. https://doi.org/10.1177/1934578x1400900308

PATOCKA, J., NAVRATILOVA, Z., OVANDO-MARTÍNEZ, M. 2017. Biologically active compounds of knotweed (Reynoutria spp.). In Mil. Med. Sci. Lett. (Voj. Zdrav. Listy), vol. 86(1), p. 17-31. https://doi.org/10.31482/mmsl.2017.004

SAITO, M., KAWAI, Y., YAMAZAKI, K., INOUE, N., SHINANO, H. 1997. Antimicrobial activities of extracts from Sachaline Giant Knotweed Polygonum sachalinense. In Food Sci Technol Int Tokyo, vol. 3(3), p. 290-93.

SVIDENKO, L., GRYGORIEVA, O., VERGUN, O., HUDZ, N., HORČINOVÁ SEDLÁČKOVÁ, V., ŠIMKOVÁ, J., BRINDZA, J. 2018. Characteristic of leaf peltate glandular trichomes and their variability of some Lamiaceae Martinov family species. In Agrobiodiversity for Improving Nutrition, Health and Life Quality, vol. 2, p. 124-132. https://doi.org/10.15414/ agrobiodiversity.2018.2585-8246.124-132

VINOGRADOVA, YU.K., MAYOROV, S.R., KHOROON, L.V. 2010. Chernaya kniga flory Srednej Rossii [The Black Book of Flora of the Middle Russia]. Moscow: GEOS. 512 p. [In Russian].

VINOGRADOVA, YU.K., KUKLINA, A.G., TKACHEVA, E.V. 2017. Stroenie cvetka u rastenij gibridogennogo kompleksa Reynoutria Houtt. In Sistematika $i$ evolyucionnaya morfologiya rastenij [Flower structure in plants of the hybrid complex Reynoutria Houtt. In Systematics and evolutionary morphology of plants: ]: Mat-ly konferencii, posvyashchennoj 85-letiyu so dnya rozhdeniya V.N. Tihomirova (31.01-03.02 2017, Moskva)/Sokolov D.D. i dr. M. MAKS Press. p. 124-129 [In Russian].

VINOGRADOVA, Y.K., GRYGORIEVA, O.V., VERGUN, E.N. 2021. Stomatal structure in Symphyotrichum nees species as an additional index of invasiveness. In Russian Journal of Biological Invasions, vol. 12, p. 27-35. https://doi.org/10.1134/S2075111721010136

ZHANG, X-G., MA, G-Y, KOU, F., LIU, W-J., SUN, Q-Y., GUO, C-J., MA, X-D., GUO, S-J., ZHU, J-N. 2019. Reynoutria Japonica from traditional chinese medicine: a source of competitive adenosine deaminase inhibitors for anticancer. In Comb Chem High Throughput Screen, vol. 22(2), p. 113-122. https://doi.org/10.2174/1386207322666190415100 $\underline{618}$ 